\title{
Model of Range CBR Distance Experienced by Transmissions in MANETs using Location-Aware Transmission for Ubicomp.
}

\author{
M. Kaleem GALAMALI, Assoc. Prof Nawaz MOHAMUDALLY
}

\begin{abstract}
Management of energy consumption of nodes in ubicomp can be assisted by location-aware transmission strategies in MANETs [64]. It is hence understandable that several development in this field will follow in the future. Among the developments projected, some refined location-aware transmission protocols may be expected. Such transmission protocols will consider several criteria to achieve successful optimal transmission, one of which is distance coverage required and selection of that protocol which best suit that distance coverage. For advanced ubicomp environment refinements of transmission protocols is projected to be granulated at $10 \mathrm{~m}$ accuracy as available in Bluetooth. Hence, even for a ubicomp topography of $300 \times 300 \mathrm{~m}^{2}$, many different protocols adopted for different distance coverages will be available.
\end{abstract}

To enable appropriate tuning of transmission in such a situation, it is desirable to know what the range of distance coverage that is being required for the CBR is and proactively activate the appropriate protocols. Such kinds of information will be based on known trends of occurrences of ranges for CBR in such topographies.

Three previous studies [26-28] had been carried out over which results for this study is built over. This paper adds a fourth component derived from PPD [26] to the area of modelling for managing distance packets travel in ubicomp topography of varying node densities. Designers may use these results towards designing more successful proactive activations of appropriate transmission protocols in ubicomp. This research is a follow-up of several previous papers [1-28].

Key terms: Ubicomp- Ubiquitous Computing, MAUCMobile and Ubiquitous Computing, MANET- Mobile Adhoc Network, PPD- Packets_Per_Distance, Max_CBR_Dist- Maximum CBR Distance, Min_CBR_Dist- Minimum_CBR_Distance, CBRConstant Bit Rate, R_CBR_Dist - Range_CBR_Distance.

M. Kaleem GALAMALI,

University of Technology Mauritius (student)

Mauritius

Assoc. Prof Nawaz Mohamudally

University of Technology Mauritius, Mauritius

\section{Introduction}

Energy consumption in MAUC is predominantly affected by distance coverages. The effect of distance of transmission is very consequent since energy consumption varies proportional to the square of distance coverages by packets [15]. In MANETs, sender node sends packets to its closest "yet unused" neighbour and this process of forwarding to yet unused neighbour is repeated until the receiver node is found. Nodes in ubicomp environment will be mobile and hence topology will be changing dynamically. Hop distances will not be of equal distances for each CBR

Transmission may carried out using protocols which are optimised corresponding to distance coverage needs. Advanced ubicomp environment may have their transmission protocols granulated at $10 \mathrm{~m}$ accuracy (as in Bluetooth). As such it can imply that many protocols need to be activated to satisfy successful transmission needs. This scope of protocols to be activated will be directly concerned with duration of transmission and expected range of distance coverage for a CBR. In this research, the second consideration "expected range of distance coverage" is probed further. The research questions put forward are: "What are the ranges of hop distances experienced by each CBR? What are the observable trends for these ranges of hop distances and how they vary with varying node densities?"

Three preceding pieces of research have been carried out whereby in each, a metric for assessing distance coverages in MANET has been elaborated: PPD [26], Max_CBR_Dist [27] and Min_CBR_Dist [28]. At first glance, the range being looked for is obtained by the difference between Max_CBR_Dist and Min_CBR_Dist and hence results being required would be obtained by comparing the two previous papers [27, 28]. However, the exact correspondence for a Min_CBR_Dist value and Max_CBR_Dist value for each CBR is not obtainable with these 2 papers. As such, the values being required had to be processed separately in the experiments and tabular results generated separately. The results obtained were also of different order. It is also recalled that for Max_CBR_Dist assessment, the \% CBR against Max_CBR_Dist was analysed whereas for Min_CBR_Dist, the cumulative \% CBR against Min_CBR_Dist was analysed. Hence, comparing two intrinsically different assessment is very difficult and explicit processing and results generation for this study is necessary. 
The key contributions of this paper is firstly, the development of a third derived metric R_CBR_Dist, derived from PPD for CBR Packet Per Distance analyses. The definition and rationale of metric R_CBR_Dist is put forward. Secondly, the model of trend is put forward for the metric R_CBR_Dist with results for varying node densities from 7 until 56 in a topography of $300 \times 300 \mathrm{~m}^{2}$. The model proposed is the normal distribution model. The rest of this paper is organised as follows: section 2- New Derived Metric Range_CBR_Distance, section 3- R_CBR_Dist Trend Assessment over Varying Node Numbers, 4Conclusion and References.

\section{New Derived Metric - Minimum_CBR_Distance.}

Following definition of PPD [26], Max_CBR_Dist [27] and Min_CBR_Dist [28], R_CBR_Dist is defined as

$$
\text { R_CBR_Dist }=\text { Max_CBR_Dist }- \text { Min_CBR_Dist }
$$

MANET routes may vary during a CBR transmission. Here also, it is envisageable that value " 0 " for metric R_CBR_Dist may be obtained, corresponding to the following scenarios:

i. A sender transmitted directly to the receiver, being closest and both were immobile.

ii. A short duration CBR obtaining MANET nodes where each node is at the same distance from the previous node in the MANET route as the sender and first relay node. All nodes concerned are immobile. This possibility remains of extremely low probabilities.

The results of this study will serve same purposes as described in previous paper [26]. An additional purpose it can serve will be deciding the range of protocols that will be needed to be proactively enabled for a CBR for a sender and each of the CBR MANET Route nodes.

\section{R_CBR_Dist - Trend Assessment over Varying Node Numbers.}

3.0 Major Observations.

Here, the plots for node numbers 7 until 56 are quite scattered but the normal distribution is clearly visible.

The x-coordinate of the peak values tend to increase with increasing node numbers.

At first glance, the plots resemble those in previous paper [27] for corresponding node numbers but as depicted in the parameter values, they are different.

Overall, the trend of the plots have fairly followed normal distribution of the form:

$F(x)=b *(1 /(a * \operatorname{sqrt}(2 * p i))) * \exp \left(-(x-c)^{2} / 2 * a * a\right)$

It can also be read as $\mathrm{F}(\mathrm{x})$ equals to a factor (b) times the equation of a normal curve.

\subsection{Tabular Summary of Results.}

A tabular summary for results of equations of curves $(\mathrm{F}(\mathrm{x}))$ is shown below. Column headings are: $\mathrm{A} \rightarrow$ node number, $\mathrm{B} \rightarrow$ Value of parameter a, $\mathrm{C} \rightarrow$ Value of parameter $\mathrm{b}, \mathrm{D} \rightarrow$ value of parameter $\mathrm{c}$ (the adjusted mean), $\mathrm{E} \rightarrow$ reduced chi-square value of plot $\mathrm{F}(\mathrm{x}), \mathrm{G} \rightarrow$ Corresponding figure number.

\begin{tabular}{|c|c|c|c|c|c|}
\hline $\mathbf{A}$ & B & $\mathbf{C}$ & D & $\mathbf{E}$ & $\mathbf{F}$ \\
\hline 7 & 0.017031 & 0.0294171 & 206.969 & 0.0456041 & 1 \\
\hline 8 & 0.0169084 & 0.0292214 & 206.736 & 0.0481437 & 2 \\
\hline 9 & 0.0167517 & 0.0286251 & 208.159 & 0.0431373 & 3 \\
\hline 10 & 0.017459 & 0.0309979 & 211.54 & 0.041574 & 4 \\
\hline 11 & 0.0177171 & 0.0316388 & 213.698 & 0.0380903 & 5 \\
\hline 12 & 0.0168951 & 0.0293064 & 217.921 & 0.0447767 & 6 \\
\hline 13 & 0.017756 & 0.0315433 & 219.454 & 0.035697 & 7 \\
\hline 14 & 0.018674 & 0.0343219 & 222.692 & 0.0320858 & 8 \\
\hline 15 & 0.0182608 & 0.0330297 & 225.624 & 0.0400619 & 9 \\
\hline 16 & 0.0176382 & 0.0309252 & 226.488 & 0.0410426 & 10 \\
\hline 17 & 0.0166119 & 0.0286019 & 227.681 & 0.0333568 & 11 \\
\hline 18 & 0.0169277 & 0.0298567 & 229.741 & 0.0399188 & 12 \\
\hline 19 & 0.0171235 & 0.0299667 & 230.073 & 0.0354797 & 13 \\
\hline 20 & 0.0179484 & 0.0323825 & 231.385 & 0.0370234 & 14 \\
\hline 21 & 0.0190251 & 0.0353405 & 232.962 & 0.0335489 & 15 \\
\hline 22 & 0.0191551 & 0.0357278 & 232.115 & 0.0410323 & 16 \\
\hline 23 & 0.0180928 & 0.0331292 & 231.632 & 0.0433152 & 17 \\
\hline 24 & 0.0187519 & 0.0341955 & 235.503 & 0.0363283 & 18 \\
\hline 25 & 0.0186811 & 0.0342424 & 237.963 & 0.0362882 & 19 \\
\hline 26 & 0.0199883 & 0.0377361 & 235.631 & 0.0441325 & 20 \\
\hline 27 & 0.0201671 & 0.0386478 & 236.64 & 0.0427012 & 21 \\
\hline 28 & 0.0195125 & 0.0369778 & 236.621 & 0.0423056 & 22 \\
\hline 29 & 0.0204901 & 0.0400365 & 238.105 & 0.0410932 & 23 \\
\hline 30 & 0.0191734 & 0.0364952 & 238.192 & 0.0426009 & 24 \\
\hline 31 & 0.0187196 & 0.0353264 & 240.356 & 0.0456194 & 25 \\
\hline 32 & 0.0190331 & 0.0354471 & 240.662 & 0.0430769 & 26 \\
\hline 33 & 0.0195226 & 0.0367802 & 242.49 & 0.0514471 & 27 \\
\hline 34 & 0.0190338 & 0.0359375 & 245.093 & 0.0471866 & 28 \\
\hline 35 & 0.0194119 & 0.0369457 & 243.877 & 0.0533262 & 29 \\
\hline 36 & 0.0188936 & 0.0358452 & 244.123 & 0.0479859 & 30 \\
\hline 37 & 0.0194074 & 0.0377084 & 244.858 & 0.0476872 & 31 \\
\hline 38 & 0.019821 & 0.0395847 & 245.102 & 0.0406379 & 32 \\
\hline 39 & 0.0202579 & 0.0400534 & 245.45 & 0.0381814 & 33 \\
\hline 40 & 0.0202534 & 0.0399813 & 246.874 & 0.0376506 & 34 \\
\hline 41 & 0.0208265 & 0.0418555 & 245.934 & 0.0409072 & 35 \\
\hline 42 & 0.019911 & 0.0394368 & 246.085 & 0.0446 & 36 \\
\hline 43 & 0.0213386 & 0.0435245 & 248.012 & 0.0392832 & 37 \\
\hline 44 & 0.0191621 & 0.0371793 & 248.691 & 0.0511978 & 38 \\
\hline 45 & 0.0192196 & 0.0372609 & 248.844 & 0.0481406 & 39 \\
\hline 46 & 0.020642 & 0.0410851 & 248.449 & 0.0474173 & 40 \\
\hline 47 & 0.02029 & 0.0403088 & 248.468 & 0.040471 & 41 \\
\hline 48 & 0.0207482 & 0.0415482 & 249.857 & 0.0461134 & 42 \\
\hline 49 & 0.0202649 & 0.0399119 & 250.207 & 0.0482976 & 43 \\
\hline 50 & 0.0200226 & 0.0387989 & 251.711 & 0.0419738 & 44 \\
\hline
\end{tabular}


Proc. of Sixth International Conference On Advances in Computing, Electronics and Electrical Technology - CEET 2016 Copyright (C) Institute of Research Engineers and Doctors. All rights reserved.

ISBN no. 978-1-63248-109-2 doi: 10.15224/ 978-1-63248-109-2-11

\begin{tabular}{|c|c|c|c|c|c|c|c|}
\hline 51 & 0.0203386 & 0.0397882 & 251.417 & 0.0414693 & 45 \\
\hline 52 & 0.0205629 & 0.0412524 & 252.119 & 0.0349394 & 46 \\
\hline 53 & 0.0211045 & 0.0427231 & 252.344 & 0.0359787 & 47 \\
\hline 54 & 0.0210625 & 0.0425291 & 253.193 & 0.0321258 & 48 \\
\hline 55 & 0.0196856 & 0.0382472 & 252.231 & 0.0330302 & 49 \\
\hline 56 & 0.0201833 & 0.0397441 & 254.355 & 0.0364187 & 50 \\
\hline
\end{tabular}

Table 1: summary of results for R_CBR_Dist equations of curves node numbers 7-56

\subsection{Graphical Plots for Results Obtained.}

This analysis is performed in gnuplot in Linux. $\mathrm{x}$-axis distance is in meters.

\section{Node Number 7}

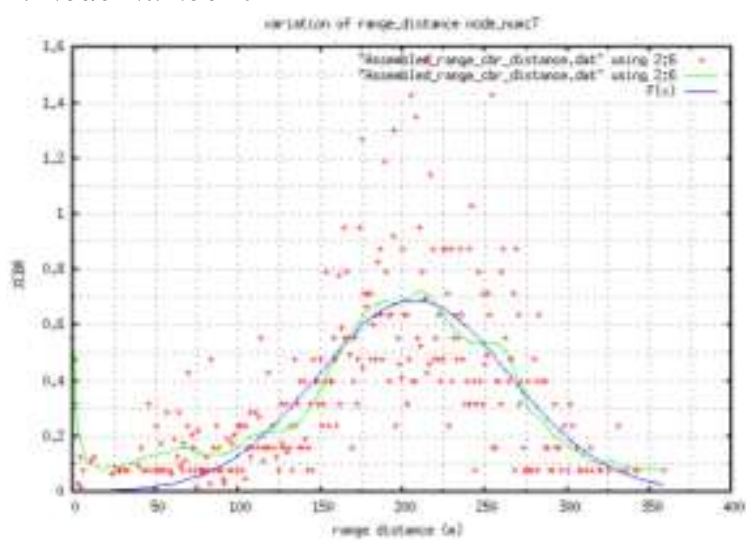

Figure 1: \% CBR against Range distance: node_number 7

\section{Node Number 8}

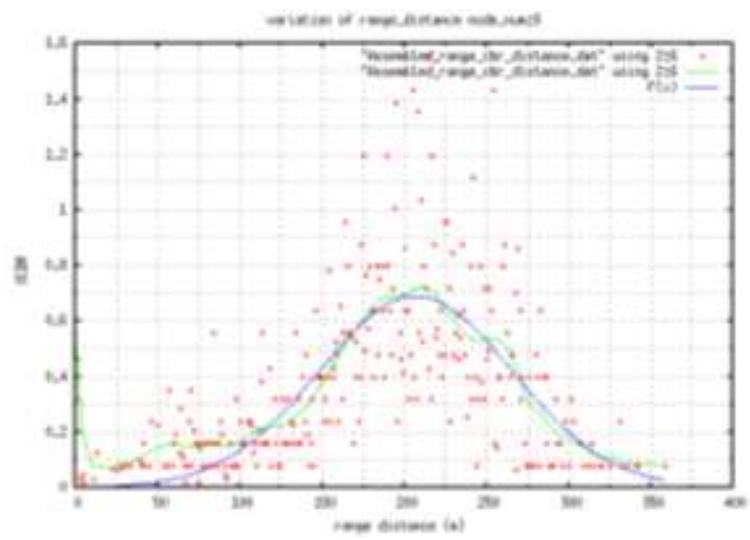

Figure 2: \% CBR Range distance: node_number 8 3. Node Number 9

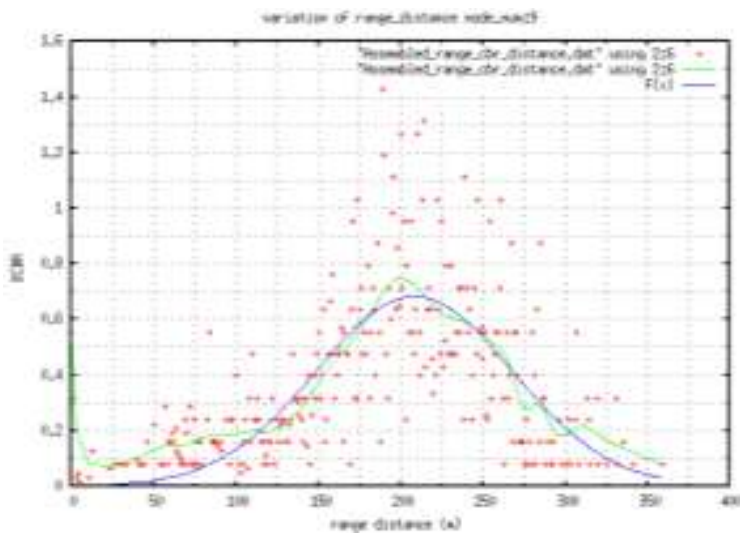

Figure 3: \% CBR Range distance: node_number 9 4. Node Number 10

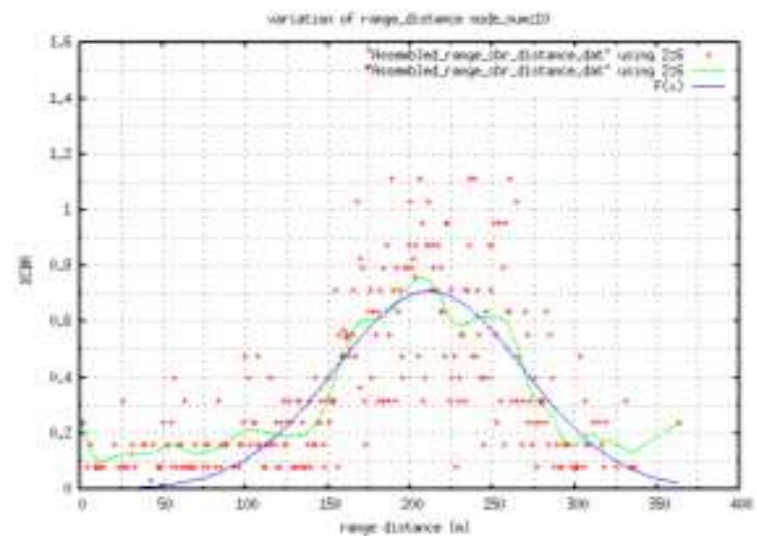

Figure 4: \% CBR Range distance: node_number 10 5. Node Number 11

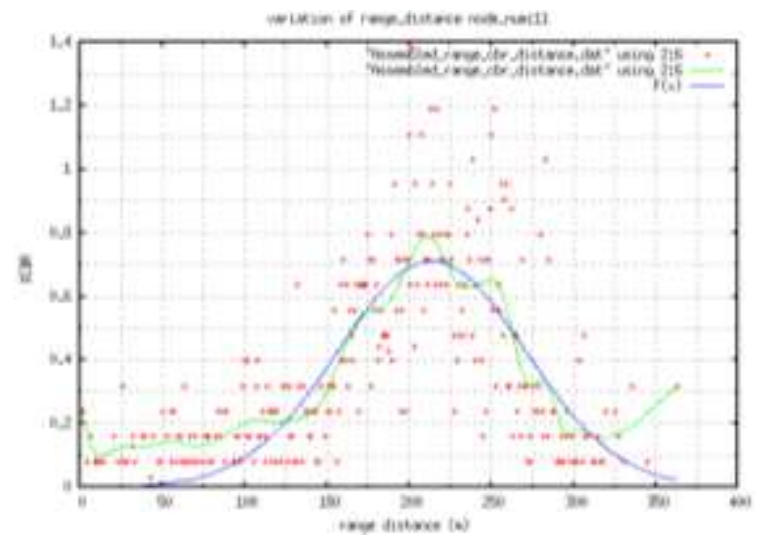

Figure 5: \% CBR Range distance: node_number 11 6. Node Number 12

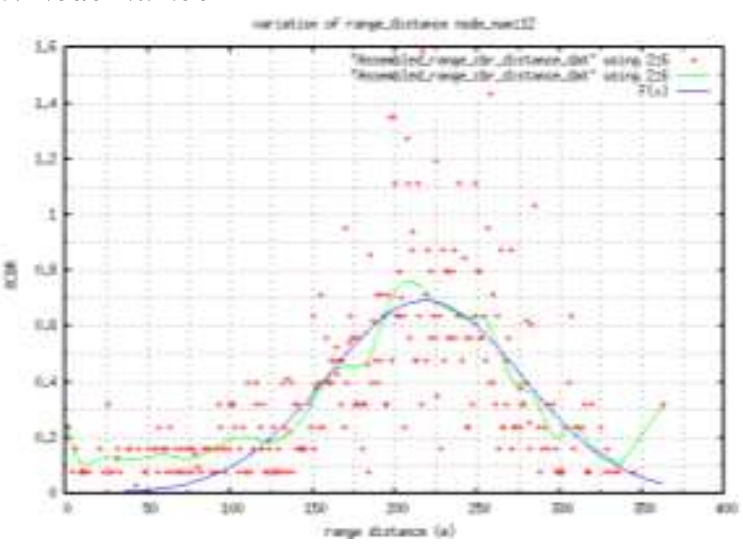

Figure 6: \% CBR Range distance: node_number 12

7. Node Number 13

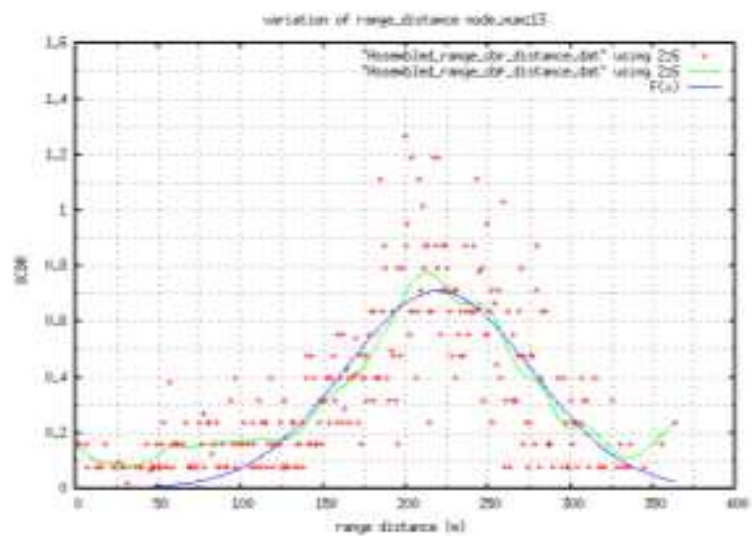

Figure 7: \% CBR Range distance: node_number 13 8. Node Number 14 
Proc. of Sixth International Conference On Advances in Computing, Electronics and Electrical Technology - CEET 2016 Copyright (C) Institute of Research Engineers and Doctors. All rights reserved.

ISBN no. 978-1-63248-109-2 doi: 10.15224/ 978-1-63248-109-2-11

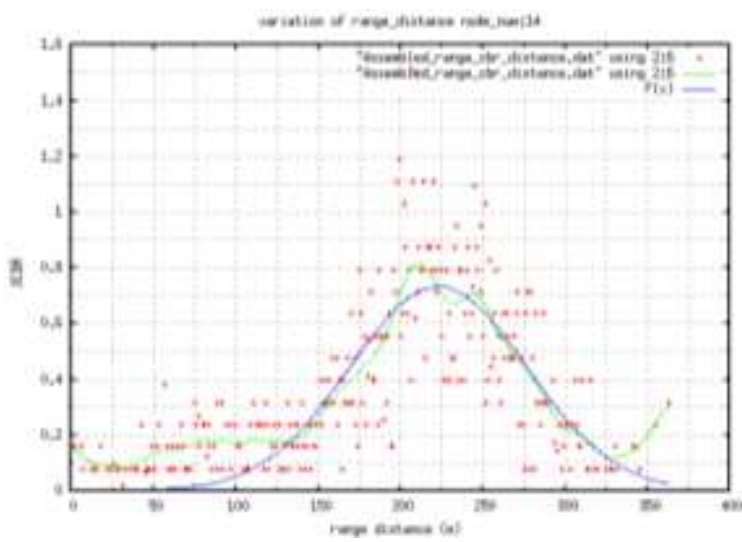

Figure 8: \% CBR Range distance: node_number 14 9. Node Number 15

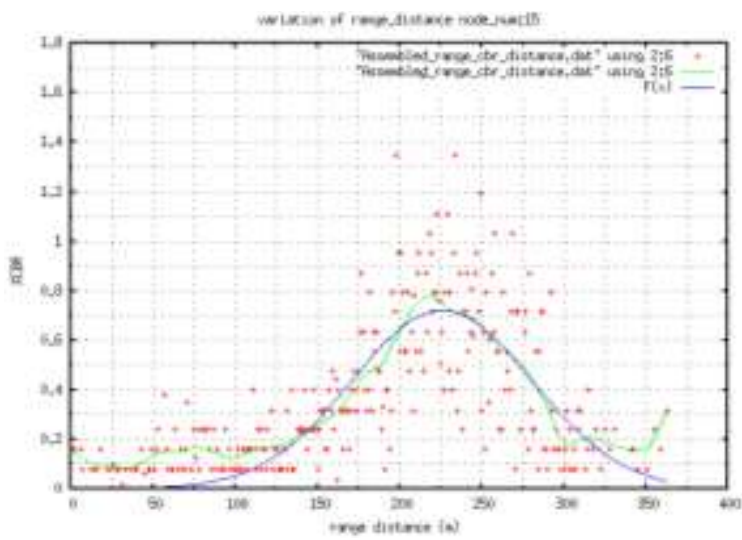

Figure 9: \% CBR Range distance: node_number 15 10. Node Number 16

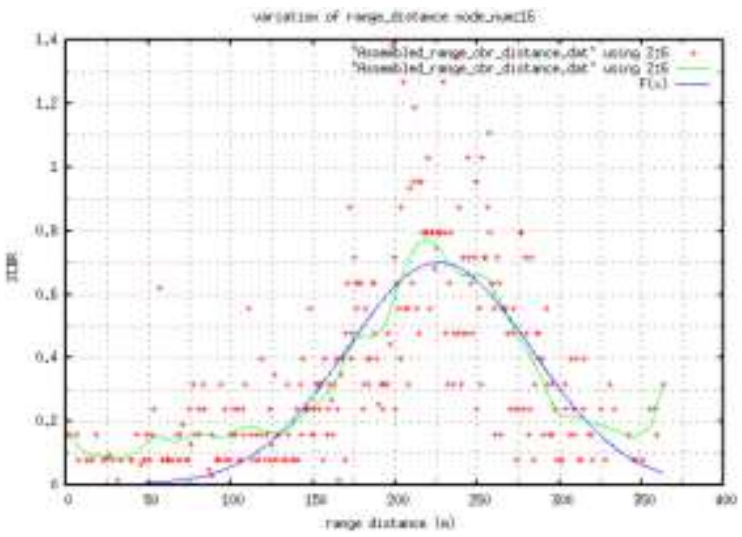

Figure 10: \% CBR Range distance: node_number 16

11. Node Number 17

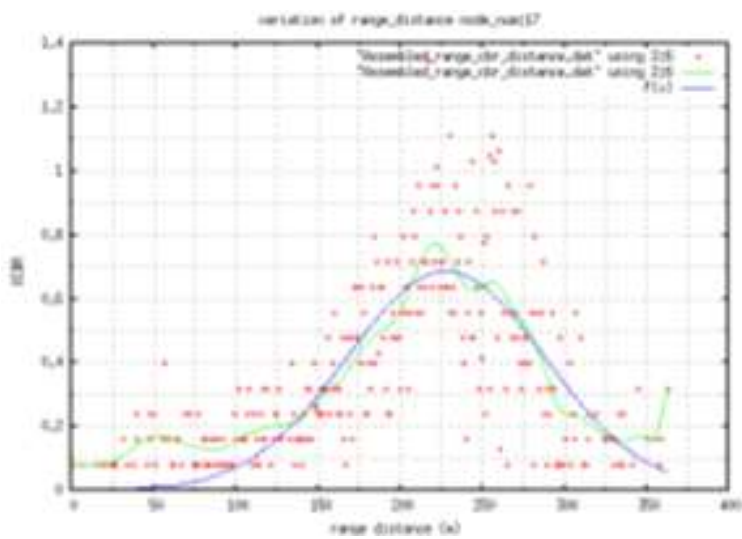

Figure 11: \% CBR Range distance: node_number 17 12. Node Number 18

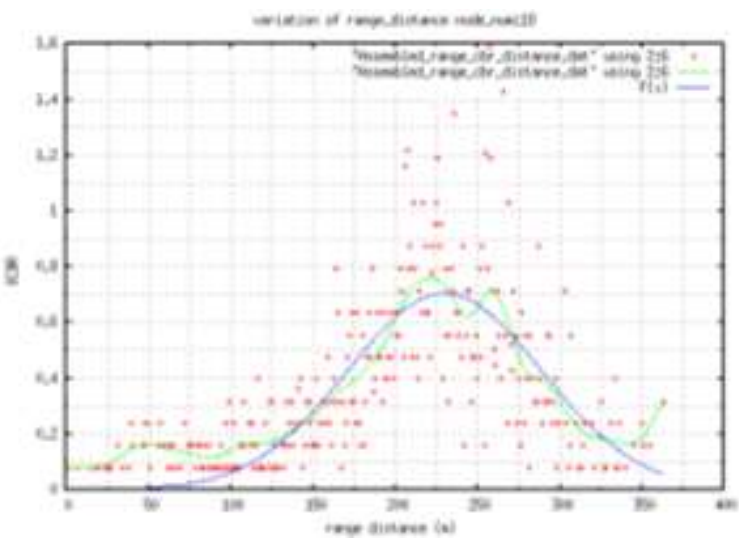

Figure 12: \% CBR Range distance: node_number 18 13. Node Number 19

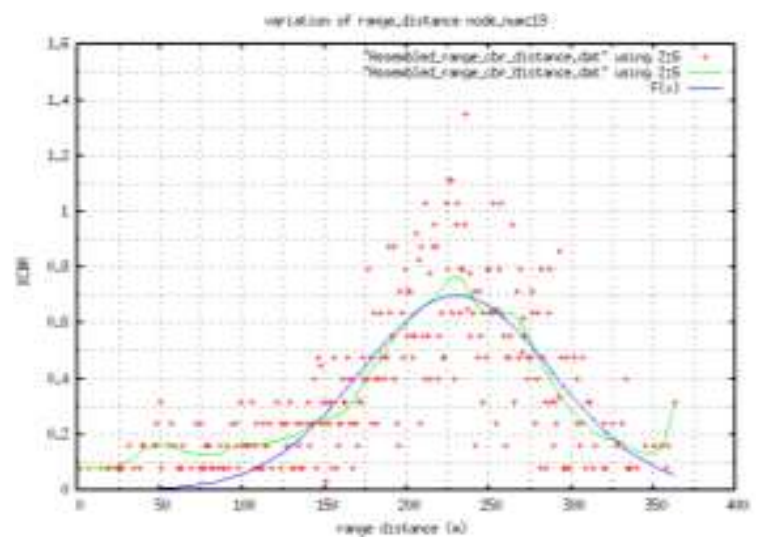

Figure 13: \% CBR Range distance: node_number 19 14. Node Number 20

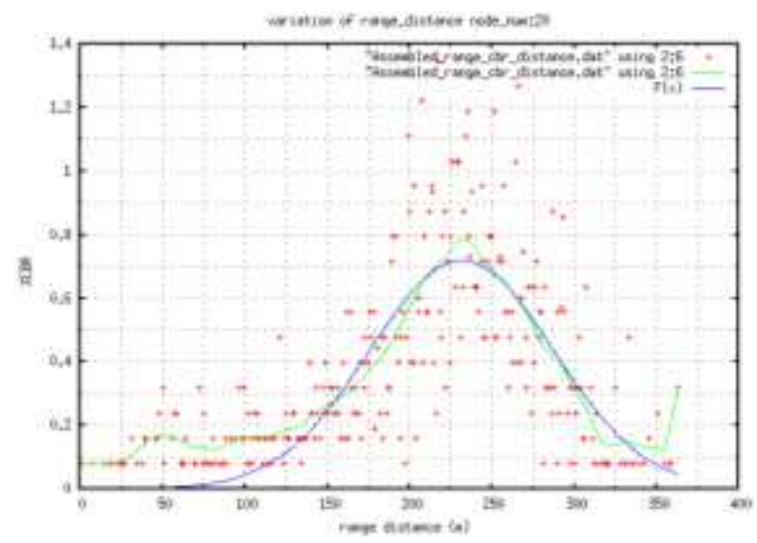

Figure 14: \% CBR Range distance: node_number 20 15. Node Number 21

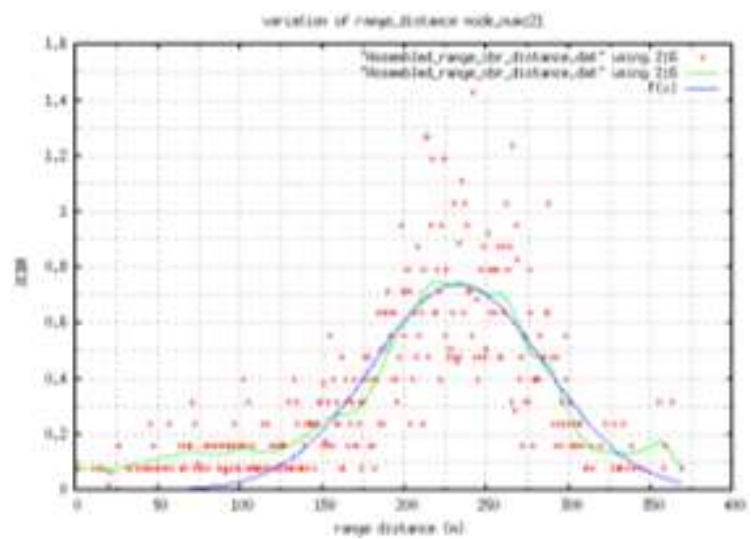

Figure 15: \% CBR Range distance: node_number 21 16. Node Number 22 
Proc. of Sixth International Conference On Advances in Computing, Electronics and Electrical Technology - CEET 2016 Copyright (C) Institute of Research Engineers and Doctors. All rights reserved.

ISBN no. 978-1-63248-109-2 doi: 10.15224/ 978-1-63248-109-2-11

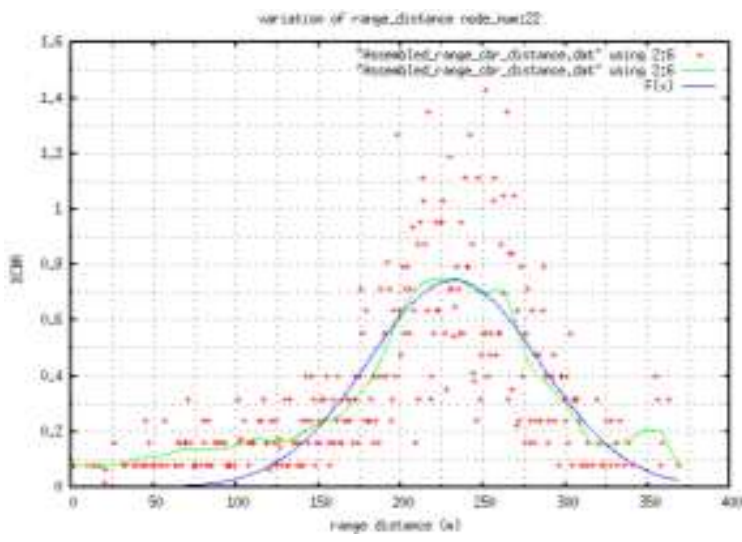

Figure 16: \% CBR Range distance: node_number 22 17. Node Number 23

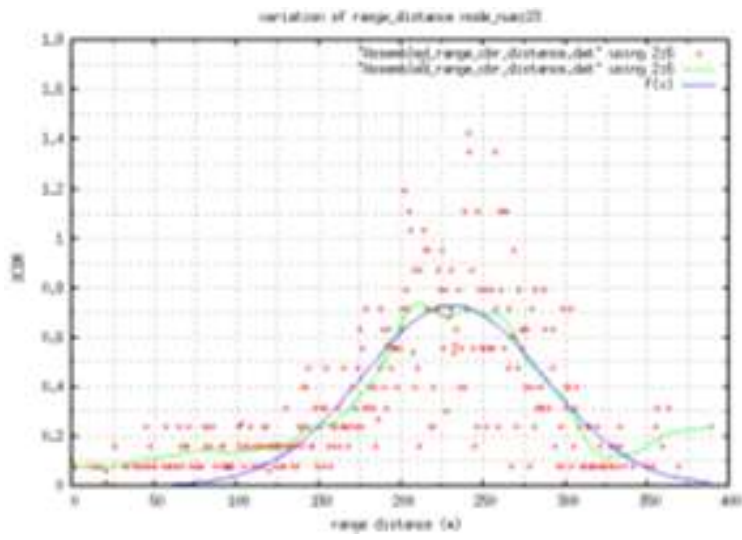

Figure 17: \% CBR Range distance: node_number 23 18. Node Number 24

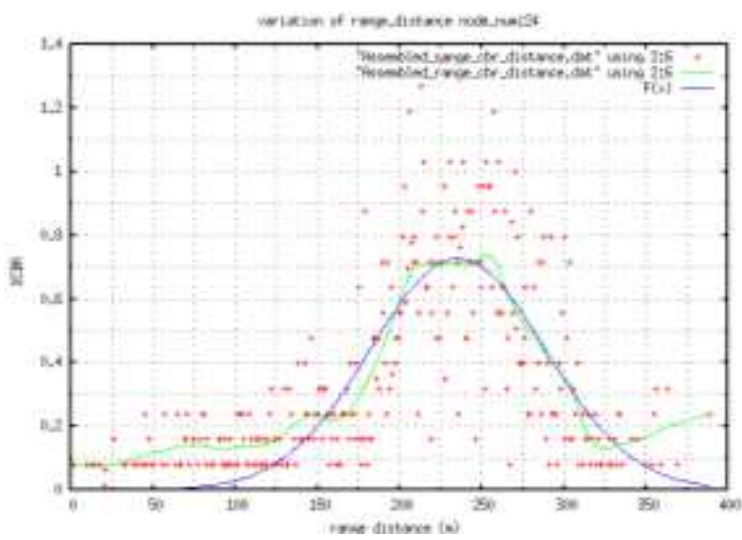

Figure 18: \% CBR Range distance: node_number 24

19. Node Number 25

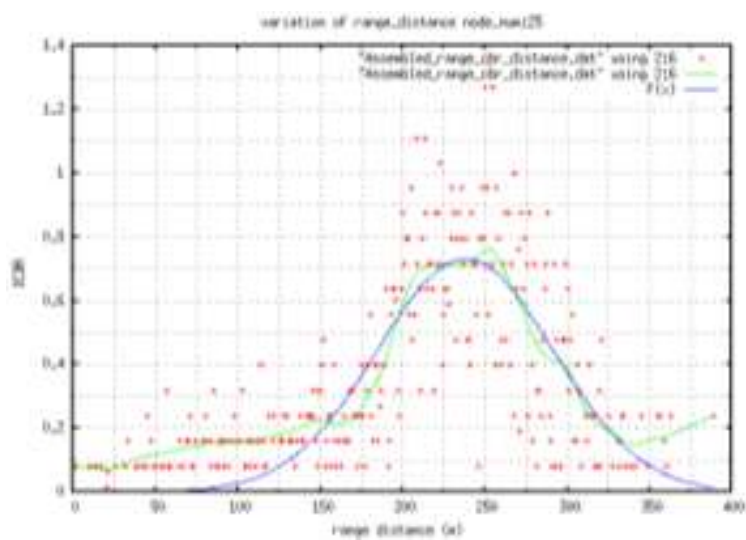

Figure 19: \% CBR Range distance: node_number 25 20. Node Number 26

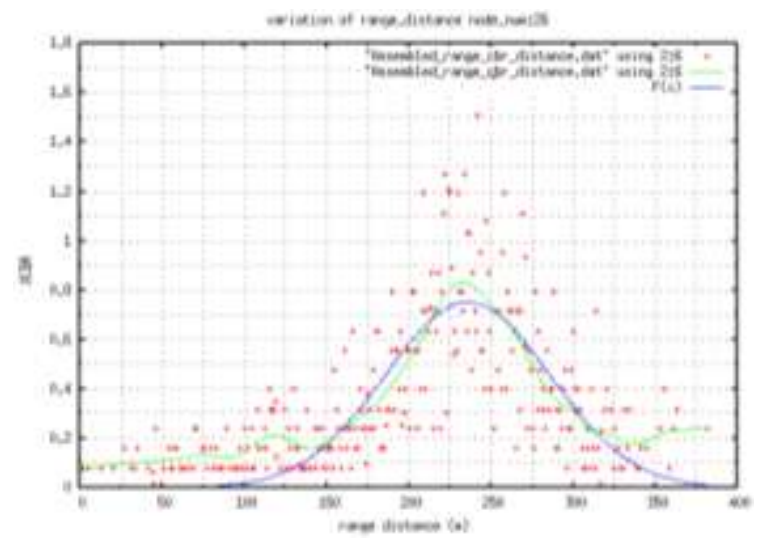

Figure 20: \% CBR Range distance: node_number 26 21. Node Number 27

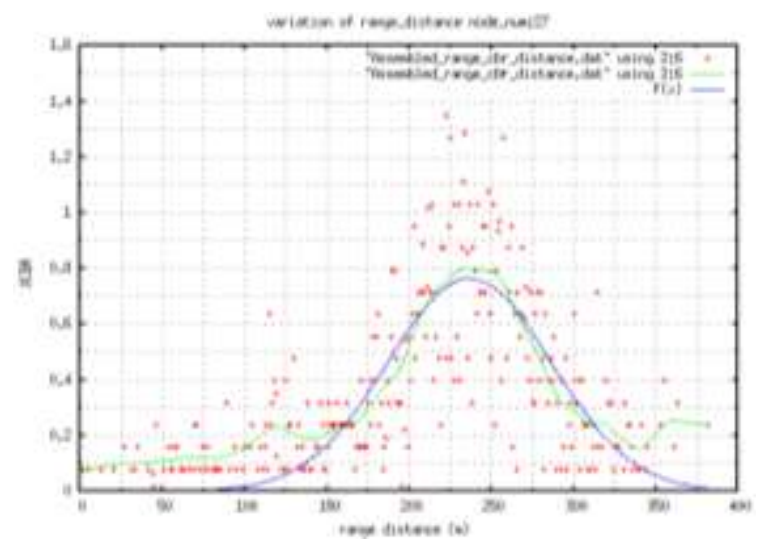

Figure 21: \% CBR Range distance: node_number 27 22. Node Number 28

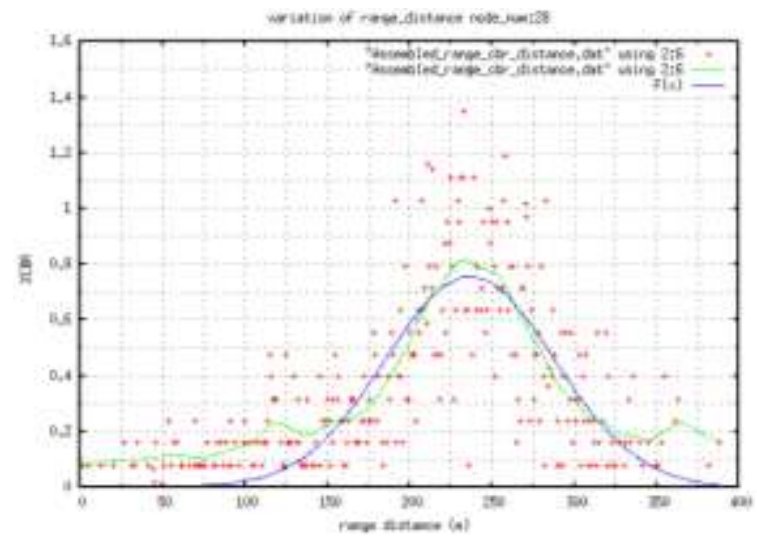

Figure 22: \% CBR Range distance: node_number 28 23. Node Number 29

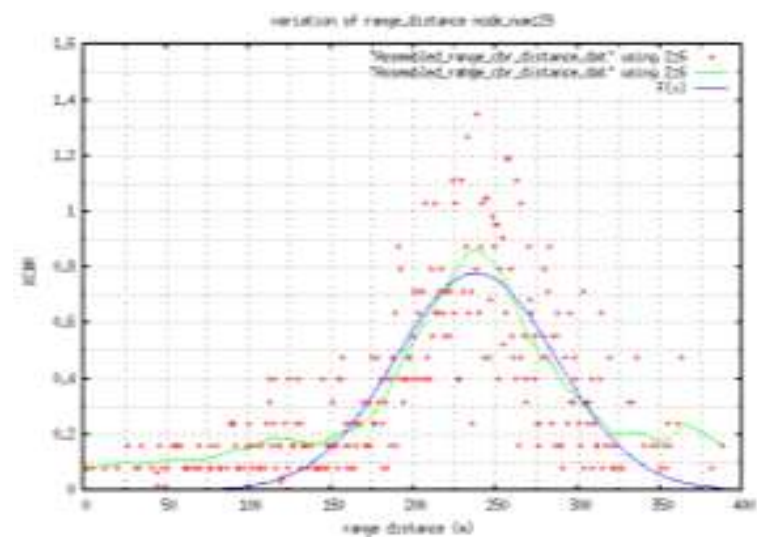

Figure 23: \% CBR Range distance: node_number 29 24. Node Number 30 
Proc. of Sixth International Conference On Advances in Computing, Electronics and Electrical Technology - CEET 2016 Copyright (C) Institute of Research Engineers and Doctors. All rights reserved.

ISBN no. 978-1-63248-109-2 doi: 10.15224/ 978-1-63248-109-2-11

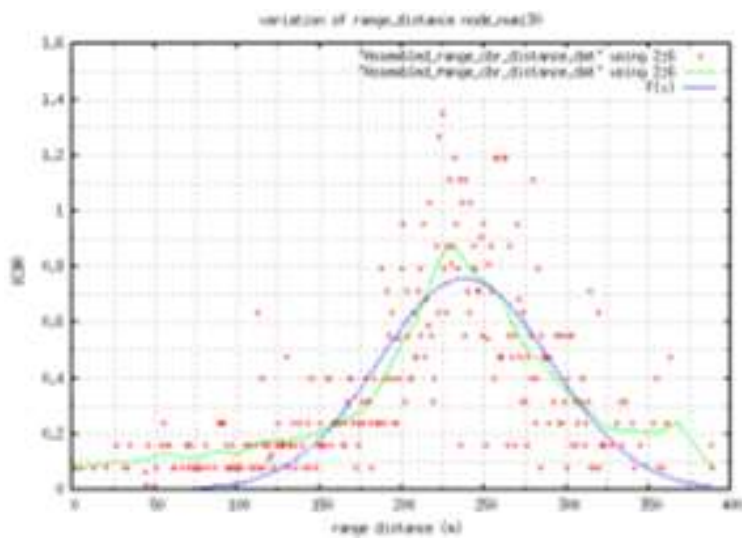

Figure 24: \% CBR Range distance: node_number 30 25. Node Number 31

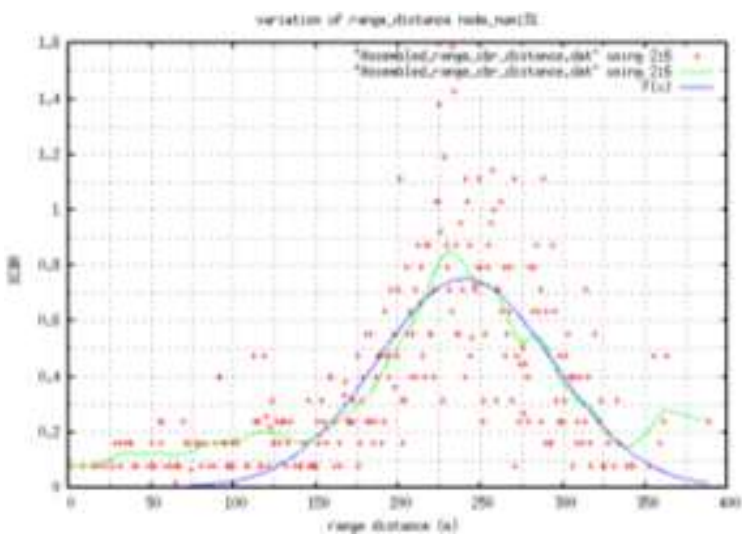

Figure 25: \% CBR Range distance: node_number 31

26. Node Number 32

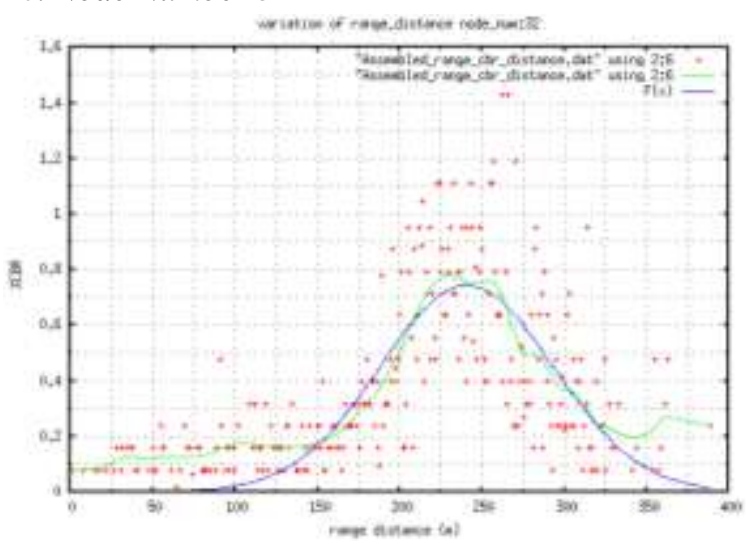

Figure 26: \% CBR Range distance: node_number 32

27. Node Number 33

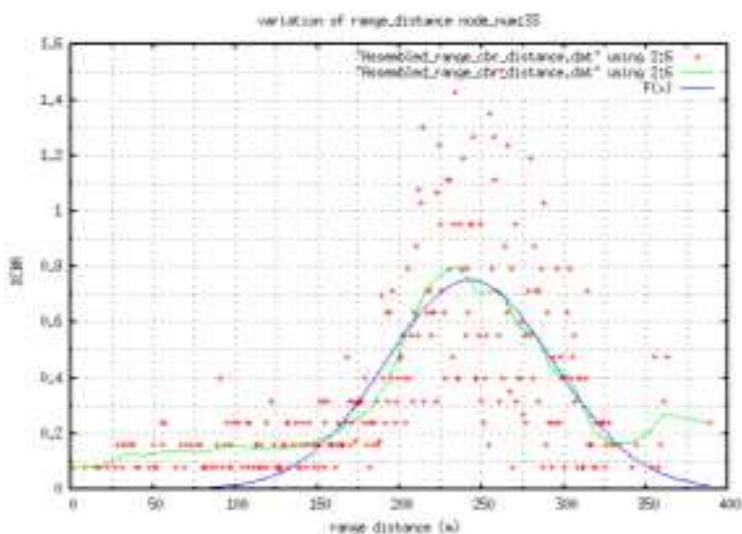

Figure 27: \% CBR Range distance: node_number 33 28. Node Number 34

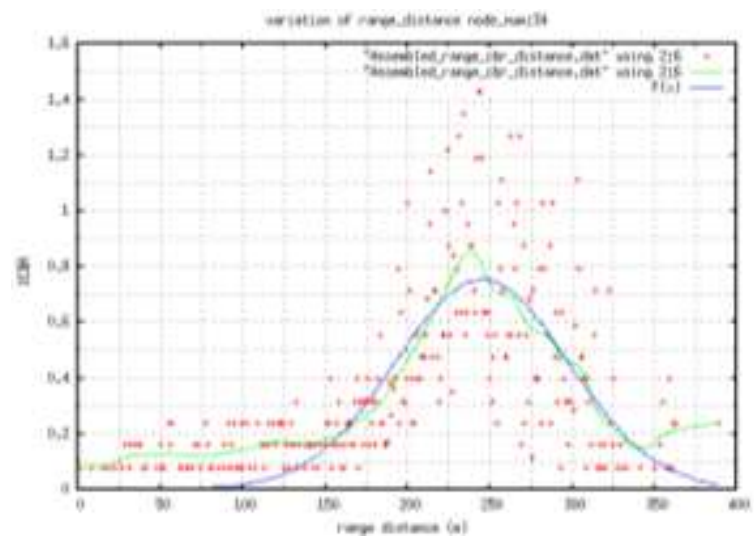

Figure 28: \% CBR Range distance: node_number 34 29. Node Number 35

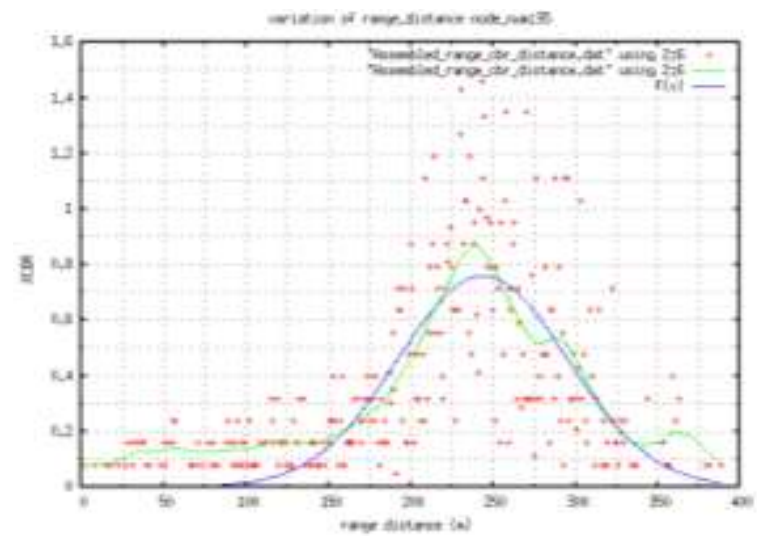

Figure 29: \% CBR Range distance: node_number 35 30. Node Number 36

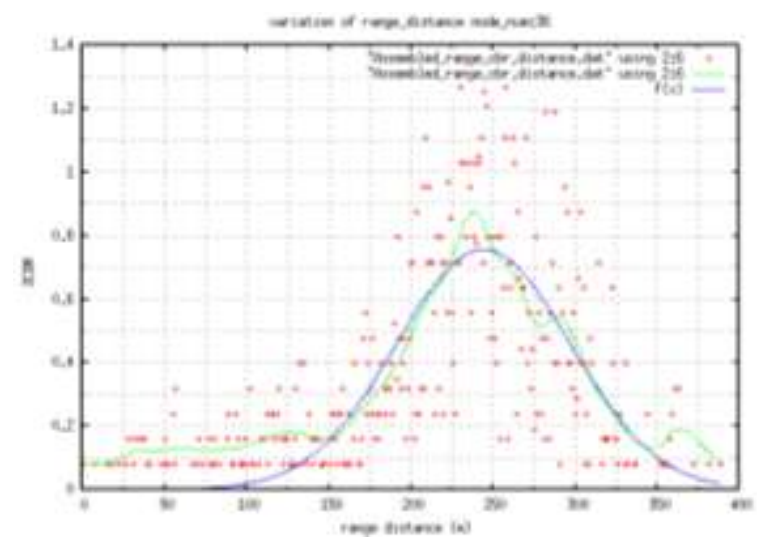

Figure 30: \% CBR Range distance: node_number 36 31. Node Number 37

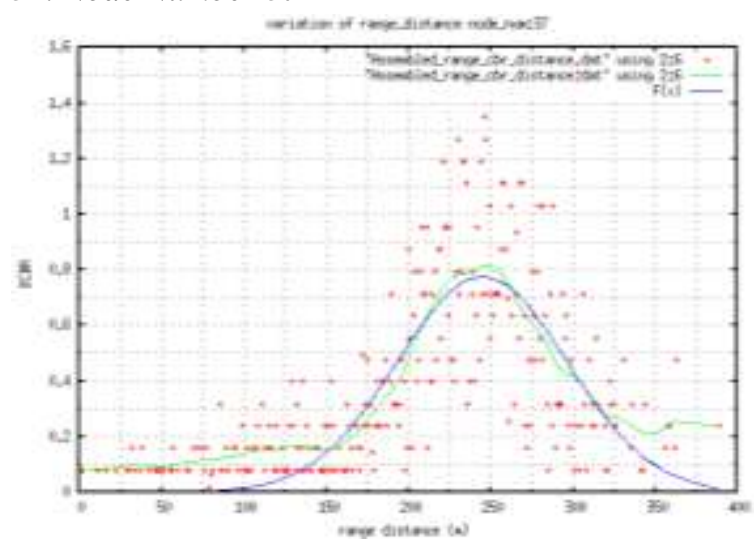

Figure 31: \% CBR Range distance: node_number 37 32. Node Number 38 
Proc. of Sixth International Conference On Advances in Computing, Electronics and Electrical Technology - CEET 2016 Copyright (C) Institute of Research Engineers and Doctors. All rights reserved.

ISBN no. 978-1-63248-109-2 doi: 10.15224/ 978-1-63248-109-2-11

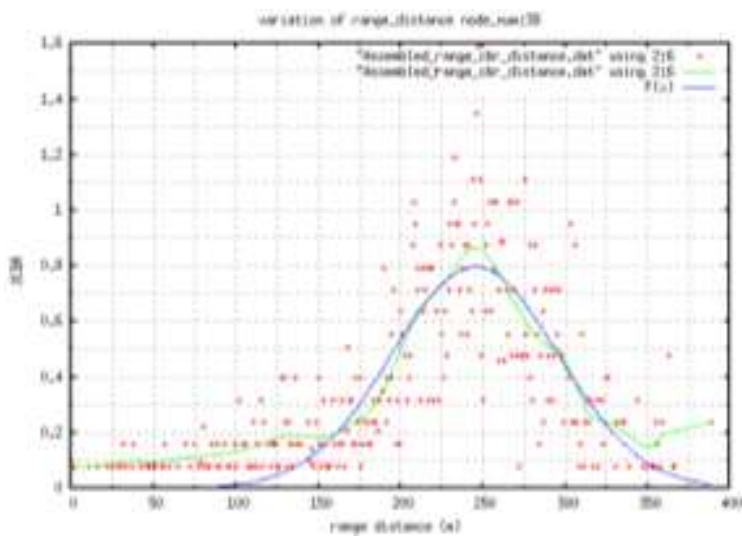

Figure 32: \% CBR Range distance: node_number 38 33. Node Number 39

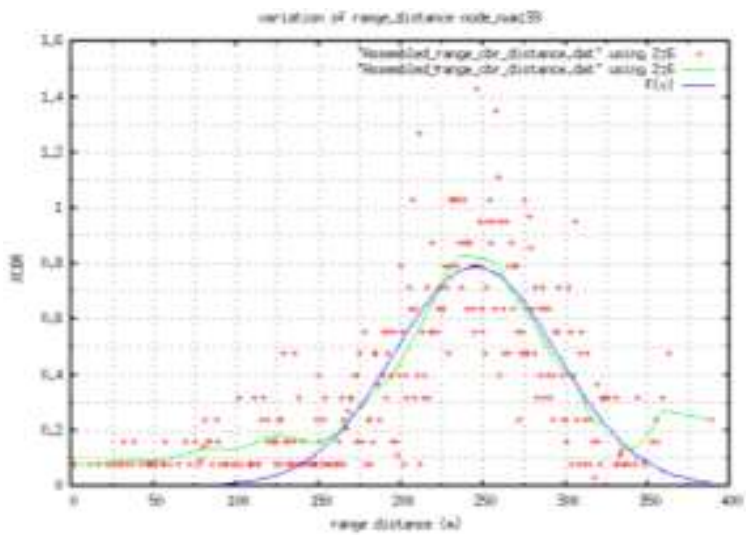

Figure 33: \% CBR Range distance: node_number 39 34. Node Number 40

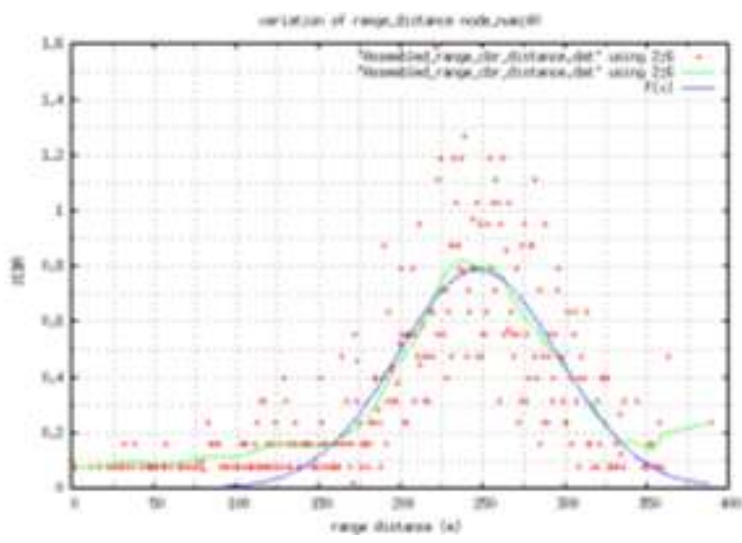

Figure 34: \% CBR Range distance: node_number 40 35. Node Number 41

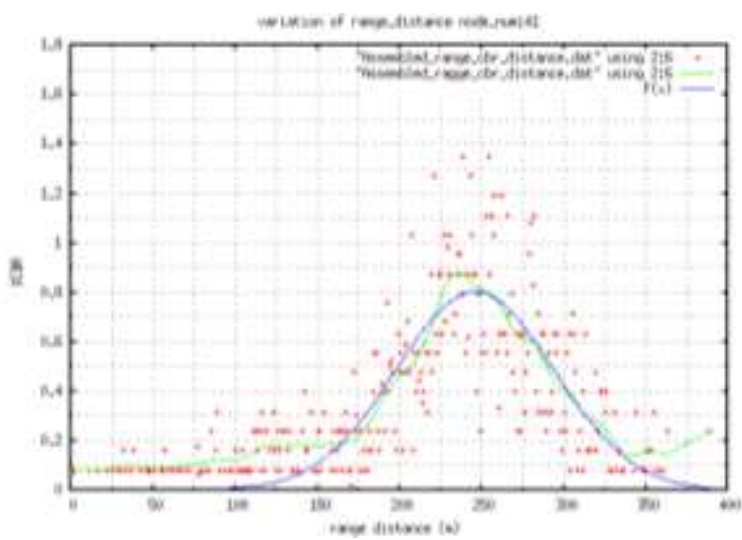

Figure 35: \% CBR Range distance: node_number 41 36. Node Number 42

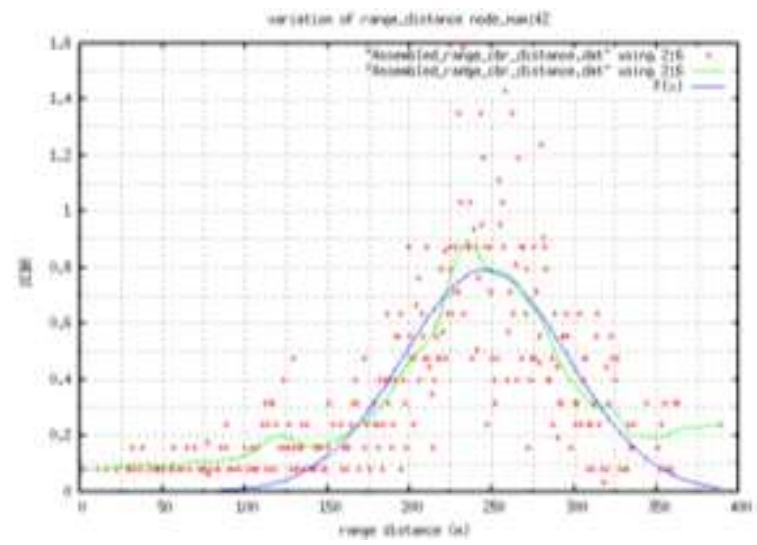

Figure 36: \% CBR Range distance: node_number 42 37. Node Number 43

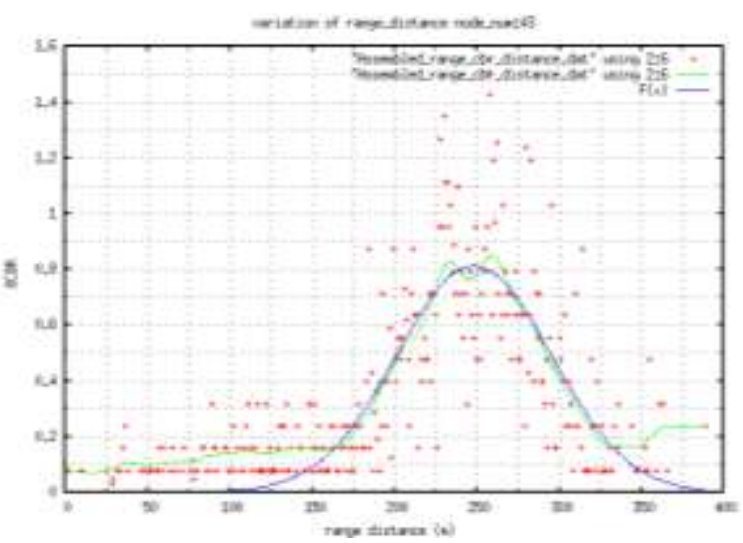

Figure 37: \% CBR Range distance: node_number 43 38. Node Number 44

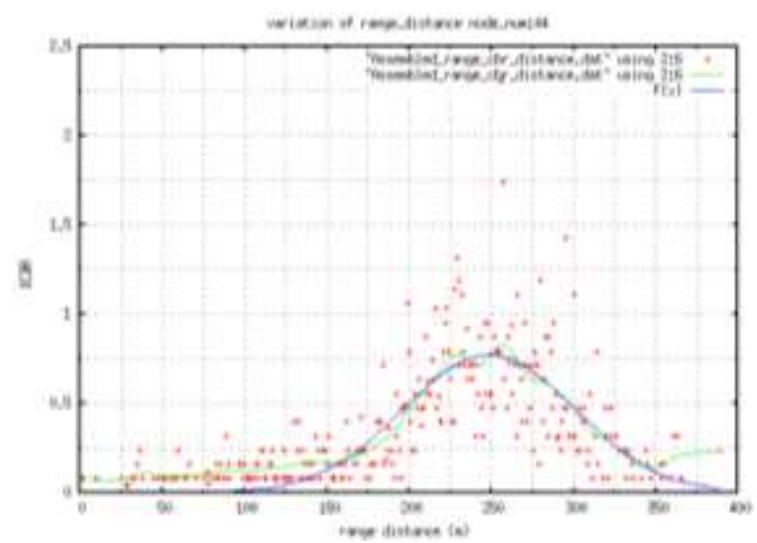

Figure 38: \% CBR Range distance: node_number 44 39. Node Number 45

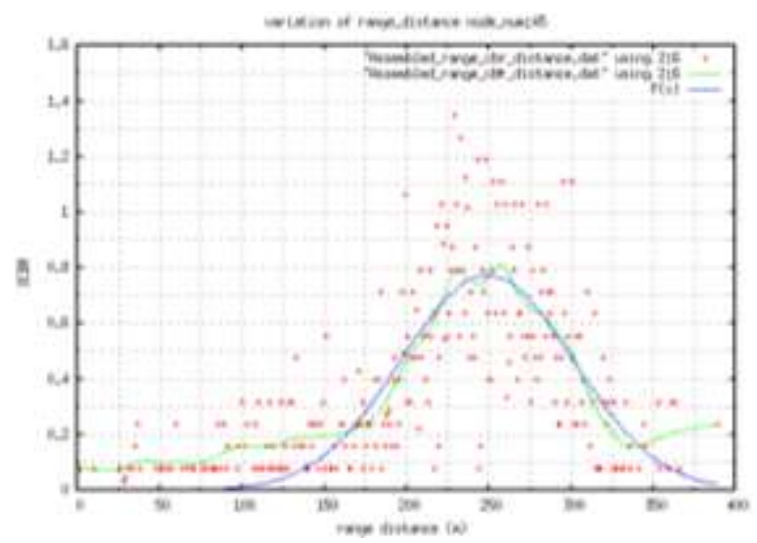

Figure 39: \% CBR Range distance: node_number 45 40. Node Number 46 
Proc. of Sixth International Conference On Advances in Computing, Electronics and Electrical Technology - CEET 2016 Copyright (C) Institute of Research Engineers and Doctors. All rights reserved.

ISBN no. 978-1-63248-109-2 doi: 10.15224/ 978-1-63248-109-2-11

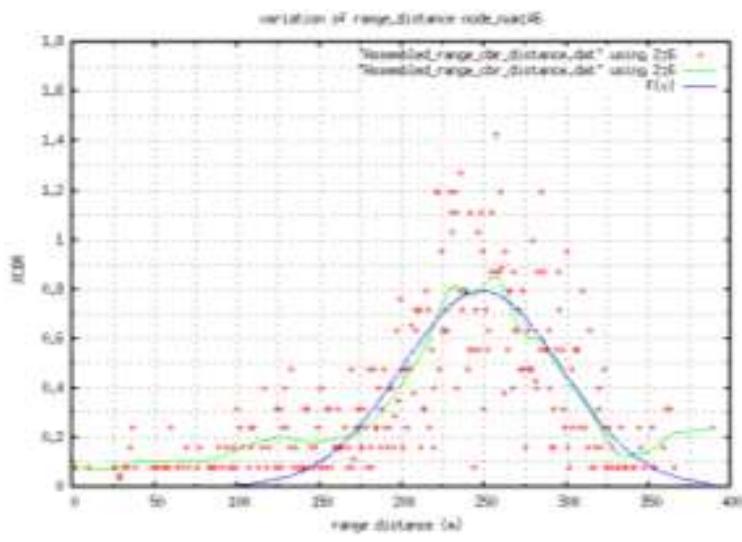

Figure 40: \% CBR Range distance: node_number 46 41. Node Number 47

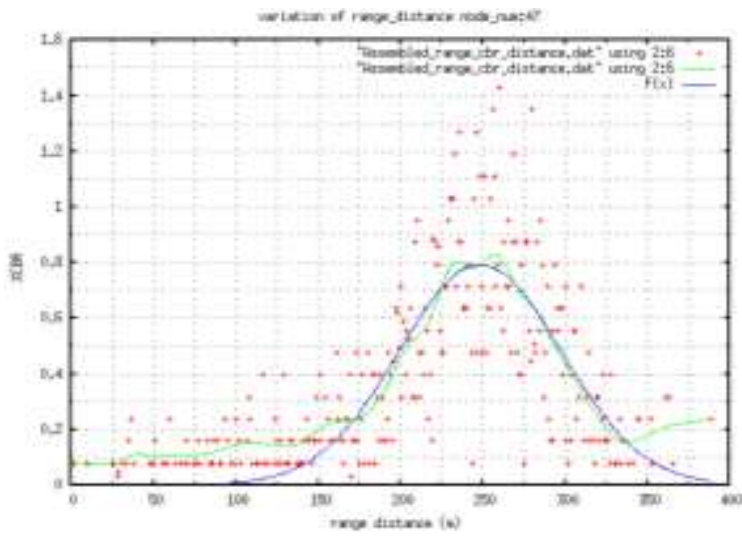

Figure 41: \% CBR Range distance: node_number 47 42. Node Number 48

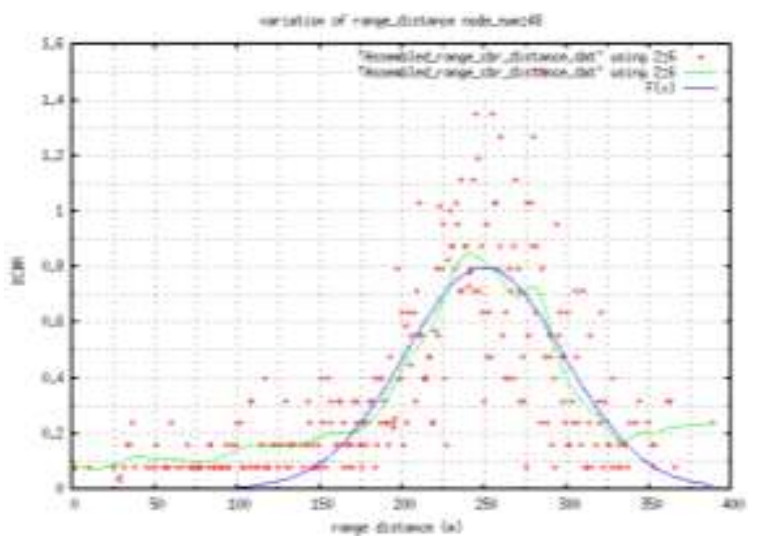

Figure 42: \% CBR Range distance: node_number 48 43. Node Number 49

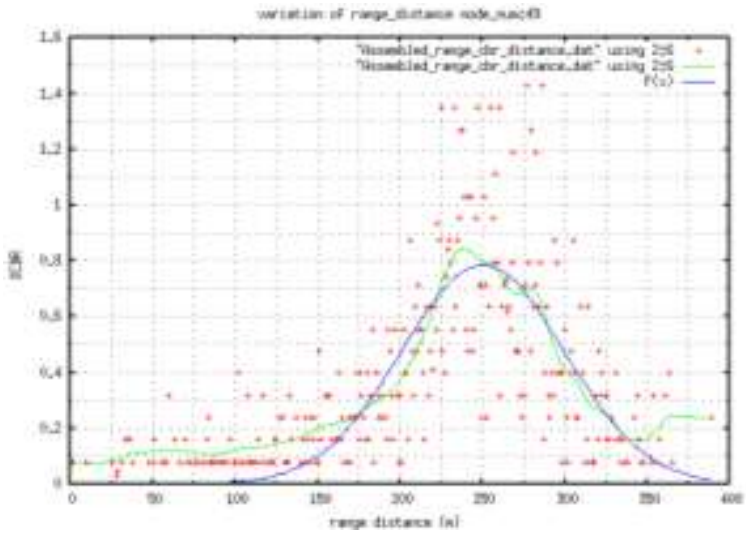

Figure 43: \% CBR Range distance: node_number 49 44. Node Number 50

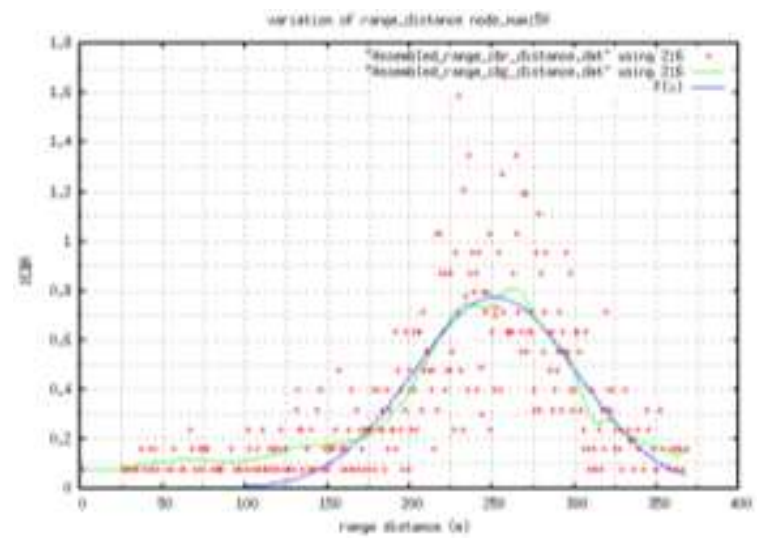

Figure 44: \% CBR Range distance: node_number 50 45. Node Number 51

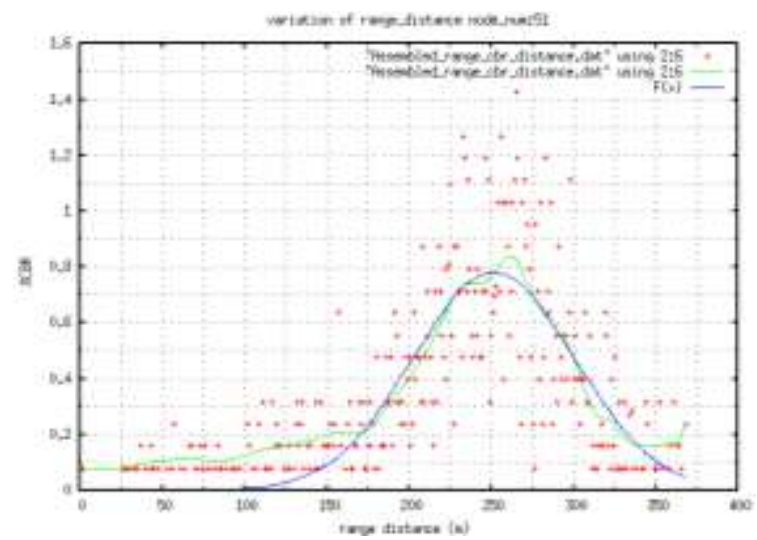

Figure 45: \% CBR Range distance: node_number 51 46. Node Number 52

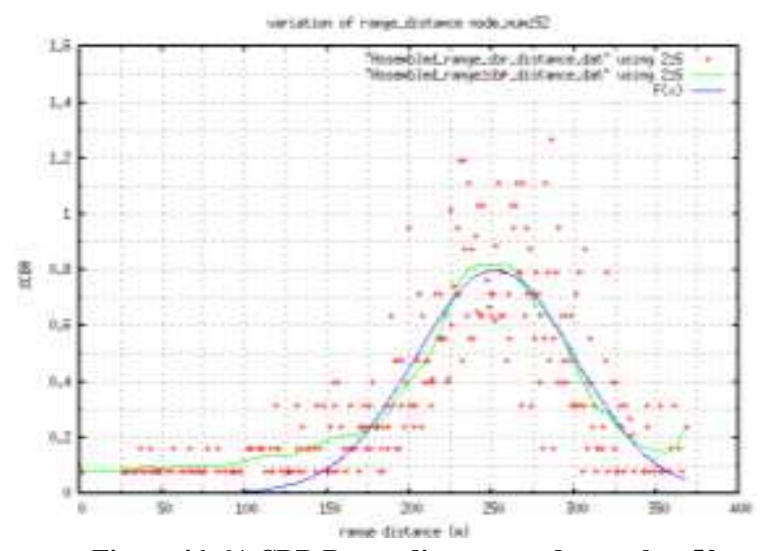

Figure 46: \% CBR Range distance: node_number 52 47. Node Number 53

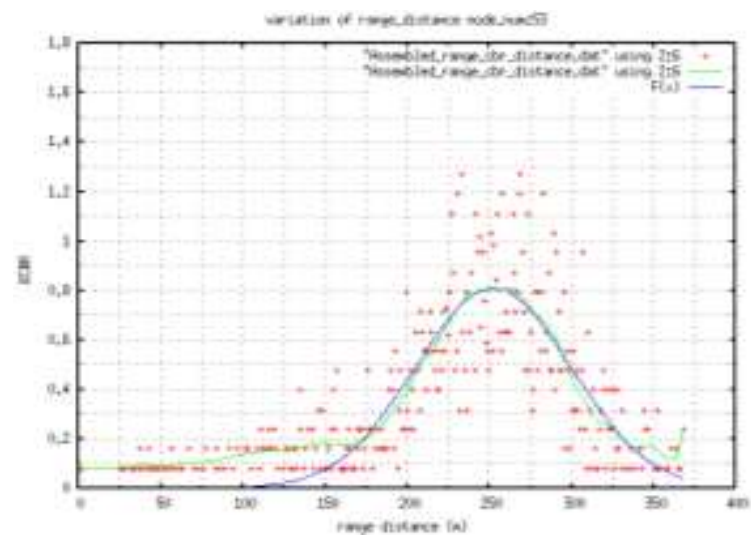

Figure 47: \% CBR Range distance: node_number 53 48. Node Number 54 


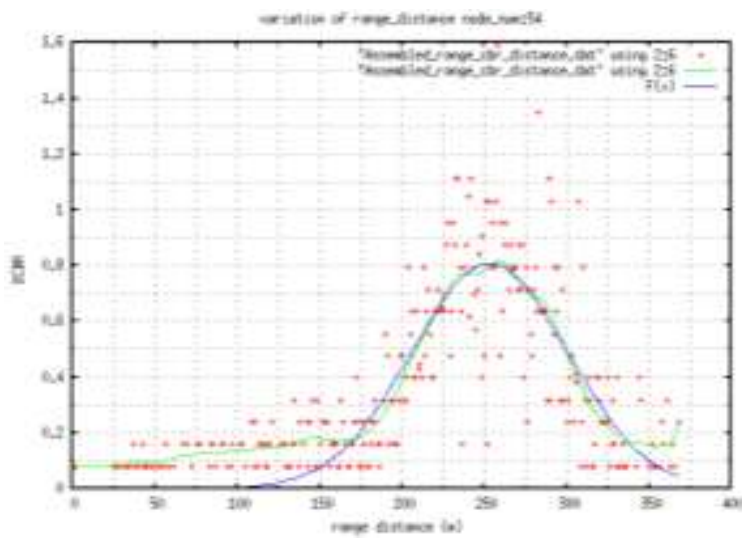

Figure 48: \% CBR Range distance: node_number 54 49. Node Number 55

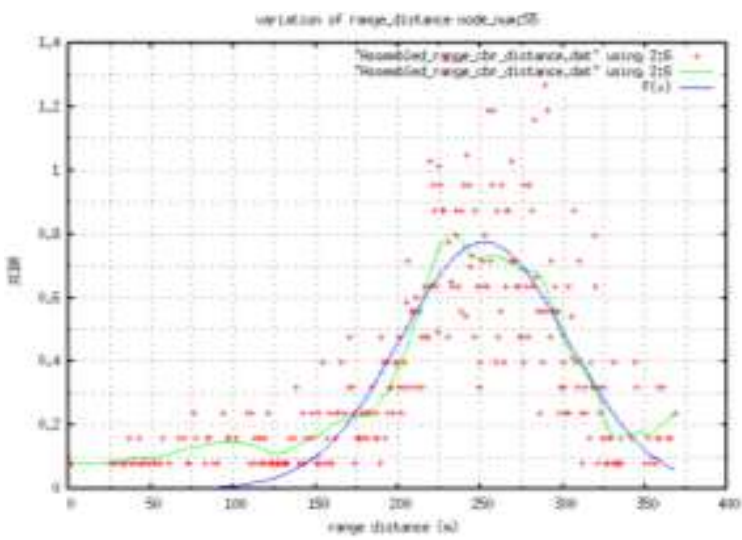

Figure 49: \% CBR Range distance: node_number 55 50. Node Number 56

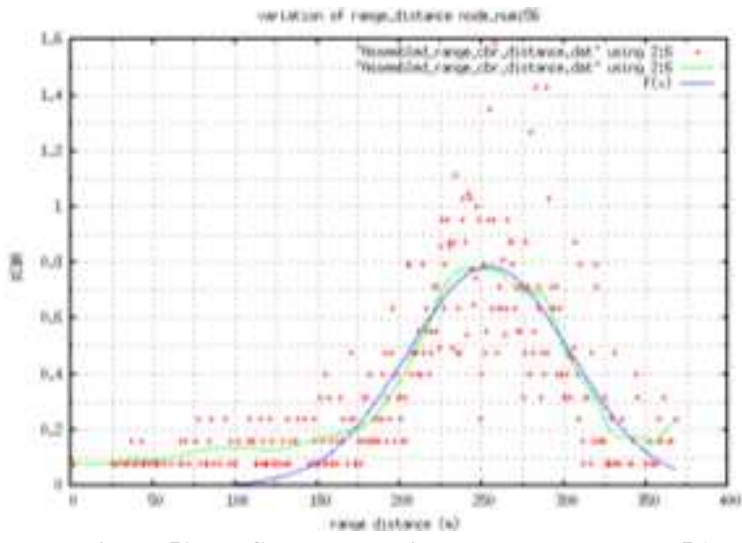

Figure 50: \% CBR Range distance: node_number 56

\section{Conclusion.}

This piece of study was aimed at studying yet another facet of distance coverages, rounded to nearest meter, experienced by CBRs in ubicomp using location-aware transmission strategies over varying node densities. This research results extends from previous research [26-28]. Though the topic of results here is directly derived after computing results of 2 previous papers $[27,28]$, a separate set of processing and plotting has been required.

More precisely here, a metric R_CBR_Dist, to assess the trend of range of distance coverages experienced by
CBRs in a ubicomp topography with varying node densities, has been developed. The experimental results here are simulation based and hence remain empirical. The model put forward here for $\%$ CBR against R_CBR_Dist is the normal distribution model.

The assumptions stated in previous paper [21] hold, e.g availability of lightweight algorithms for locationaware transmission in mobile environments, lightweight MAUC OS supports for efficient binding/unbinding of MANET nodes and appropriate multi-threading/parallel communication in modules of MANET nodes.

The further work identified may include: trend analyses of parameters of equations for the model, formulating methods of predictability for metric R_CBR_Dist and its trend and reporting observations of certain critical values identified. The purposes of this metric is also open for refinement together with its applicability in proactive activations of MANET transmission protocols. Development of other sub-component metrics derived from metric PPD remain desirable.

\section{References}

[1] M. Kaleem GALAMALI, Assoc. Prof Nawaz MOHAMUDALLY, Towards Dependable Pervasive Systems-A Position and Vision Paper, CEET 2014

[2] M. Kaleem GALAMALI, Assoc. Prof Nawaz MOHAMUDALLY, Model of Energy Savings achievable with Location-aware Node-to-Node Transmission in UbiComp , CEET 2014

[3] M. Kaleem GALAMALI, Assoc. Prof Nawaz MOHAMUDALLY, Model of Energy Savings achievable with Location-aware Node-to-Node Transmission in UbiComp Using Location Refresh Intervals, CEET 2014

[4] M. Kaleem GALAMALI, Assoc. Prof Nawaz MOHAMUDALLY, Model of Energy Savings achievable with Location-aware Transmission in UbiComp Using Relays, CEET 2014

[5] M. Kaleem GALAMALI, Assoc. Prof Nawaz MOHAMUDALLY, Mathematical modeling of need of exact number of relays to ensure seamless mobility in mobile computing, CEET 2014

[6] M. Kaleem GALAMALI, Assoc. Prof Nawaz MOHAMUDALLY, Modelling of need for multiple relays for ensuring seamless mobility, CEET 2014

[7] M. Kaleem GALAMALI, Assoc. Prof Nawaz MOHAMUDALLY, Investigation of prominence of placements of relays in a ubicomp topography,

[8] M. Kaleem GALAMALI, Assoc. Prof Nawaz MOHAMUDALLY, Model of energy savings achievable with location-aware transmission in ubicomp using optimised number of relays.

[9] M. Kaleem GALAMALI, Assoc. Prof Nawaz MOHAMUDALLY, Investigation of Prominence of Placements of Optimised Number of Relays in a Ubicomp Topography using Location-Aware Transmission, CEET 2015.

[10] M. Kaleem GALAMALI, Assoc. Prof Nawaz MOHAMUDALLY, Extending Node Battery Availability in Ubicomp with Location-Aware Transmission, CEET 2015.

[11] M. Kaleem GALAMALI, Assoc. Prof Nawaz 
MOHAMUDALLY, Extending Node Battery Availability in Ubicomp with Location-Aware Transmission using Location Refresh Intervals, CEET 2015.

[12] M. Kaleem GALAMALI, Assoc. Prof Nawaz MOHAMUDALLY, Extending Node Battery Availability in Ubicomp with Location-Aware Transmission using Uniformly Placed Relays, CEET 2015.

[13] M. Kaleem GALAMALI, Assoc. Prof Nawaz MOHAMUDALLY, Extending Node Battery Availability in Ubicomp with Location-Aware Transmission Using Optimally Placed Relays, CEET 2015.

[14] M. Kaleem GALAMALI, Assoc. Prof Nawaz MOHAMUDALLY, Model of Sender Node Energy Savings Achievable with Location-Aware MANET Transmission in Ubicomp. ACCN 2016

[15] M. Kaleem GALAMALI, Assoc. Prof Nawaz MOHAMUDALLY, Model of Overall Node Energy Savings Achievable with Location-Aware MANET Transmission in Ubicomp. ACCN 2016

[16] M. Kaleem GALAMALI, Assoc. Prof Nawaz MOHAMUDALLY, Model of Sender Node Extra Energy Savings Achievable in MANET Against Direct Node-toNode Transmission Using Location-Aware Transmission in Ubicomp. ACCN 2016

[17] M. Kaleem GALAMALI, Assoc. Prof Nawaz MOHAMUDALLY, Model of Overall Node Extra Energy Savings Achievable in MANET against Direct Node-toNode Transmission Using Location-Aware Transmission in Ubicomp. ACCN 2016

[18] M. Kaleem GALAMALI, Assoc. Prof Nawaz MOHAMUDALLY, Model of Energy Consumption Ratio Achievable in MANET Using Location-Aware Transmission in Ubicomp. ACCN 2016

[19] M. Kaleem GALAMALI, Assoc. Prof Nawaz MOHAMUDALLY, Model of Minimum Energy Consumption Ratio Achievable in MANET Using LocationAware Transmission in Ubicomp. ACCN 2016

[20] M. Kaleem GALAMALI, Assoc. Prof Nawaz MOHAMUDALLY, Model of Maximum Energy Consumption Ratio Achievable in MANET Using LocationAware Transmission in Ubicomp. ACCN 2016

[21] M. Kaleem GALAMALI, Assoc. Prof Nawaz MOHAMUDALLY, Model of Overall Energy Consumption Fairness Ratio Achievable in MANET Using LocationAware Transmission in Ubicomp. ACCN 2016

[22] M. Kaleem GALAMALI, Assoc. Prof Nawaz MOHAMUDALLY, Model of Overall Energy Consumption Fairness Proportion Achievable in MANET Using LocationAware Transmission for Ubicomp.

[23] M. Kaleem GALAMALI, Assoc. Prof Nawaz MOHAMUDALLY, Model of Minimum Fairness Proportion Achievable in MANET Using Location-Aware Transmission for Ubicomp.

[24] M. Kaleem GALAMALI, Assoc. Prof Nawaz MOHAMUDALLY, Model of Maximum Fairness Proportion Achievable in MANET Using Location-Aware Transmission for Ubicomp.

[25] M. Kaleem GALAMALI, Assoc. Prof Nawaz MOHAMUDALLY, Model of Sender Fairness Proportion Achievable in MANET Using Location-Aware Transmission for Ubicomp.

[26] M. Kaleem GALAMALI, Assoc. Prof Nawaz MOHAMUDALLY, Model of Distance Travelled by packets in MANETs using Location-Aware Transmission for Ubicomp.

[27] M. Kaleem GALAMALI, Assoc. Prof Nawaz MOHAMUDALLY, Model of Maximum CBR Distance Travelled by packets in MANETs using Location-Aware Transmission for Ubicomp.

[28] M. Kaleem GALAMALI, Assoc. Prof Nawaz MOHAMUDALLY, Model of Minimum CBR Distance Travelled by packets in MANETs using Location-Aware Transmission for Ubicomp.

[29] Markus Bylund and Zary Segall, Towards seamless mobility with personal servers, 2004

[30] Masugi Inoue, Mikio Hasegawa, Nobuo Ryoki and Hiroyuki Morikawa, Context-Based Seamless Network and
Application Control, 2004

[31] Xiang Song, Umakishore Ramachandran, MobiGo: A Middleware for Seamless Mobility, College of Computing Georgia Institute of Technology, Atlanta, GA, USA, August 2007

[32] Budzisz, Ferrús, R., Brunstrom A., Grinnemo, K, Fracchia, R., Galante, G., and Casadevall, F. Towards transport-layer mobility: Evolution of SCTP multihoming, March 2008

[33] Paul Dourish \& Genevieve Bell, Divining a digital future, 2011.

[34] Xiang Song, Seamless Mobility In Ubiquitous Computing Environments, PhD Thesis, Georgia Institute of Technology, August 2008

[35] Kevin O Mahony, Jian Liang, Kieran Delaney, User-Centric Personalization and Autonomous Reconfiguration Across Ubiquitous Computing Environments, NIMBUS Centre Cork Institute of Technology, Cork, Ireland, UBICOMM 2012

[36] Pablo Vidales, Seamless mobility in $4 \mathrm{G}$ systems, Technical Report, University of Cambridge, Computer Laboratory, Number 656, November 2005

[37] João Pedro Sousa and David Garlan, Aura: An Architectural Framework for User Mobility in Ubiquitous Computing Environments, School of Computer Science, Carnegie Mellon University, USA, August 2002

[38] Dennis Lupiana, Ciaran O'Driscoll, Fredrick Mtenzi, Defining Smart Space in the Context of Ubiquitous Computing, Dublin Institute of Technology, Ireland, Special Issue on ICIT 2009 Conference - Web and Agent Systems, 2009

[39] N.S.V.Shet1, Prof.K.Chandrasekaran2 and Prof. K.C.Shet3, WAP Based Seamless Roaming In Urban Environment with Wise Handoff Technique, International Journal of UbiComp (IJU), Vol.1, No.4, October 2010

[40] Yipeng Yu Dan He Weidong Hua Shijian Li Yu Qi Yueming Wang Gang Pan, FlyingBuddy2: A Braincontrolled Assistant for the Handicapped, Zhejiang University, UbiComp'12, September 5-8, 2012.

[41] Jing Su, James Scott, Pan Hui, Jon Crowcroft, Eyal de Lara Christophe Diot, Ashvin Goel, Meng How Lim, and Eben Upton, Haggle: Seamless Networking for Mobile Applications, 2007

[42] Rui Han, Moustafa M. Ghanem, Li Guo, Yike Guo*, Michelle Osmond, Enabling cost-aware and adaptive elasticity of multi-tier cloud applications, Future Generation Computer Systems, 2012

[43] Byrav Ramamurthy, K. K. Ramakrishnan, Rakesh K. Sinha, Cost and Reliability Considerations in Designing the NextGeneration IP over WDM Backbone Networks, 2012.

[44] Bhavish Aggarwal, Aditya Akella, Ashok Anand, Athula Balachandran, Pushkar Chitnis, Chitra Muthukrishnan, Ram Ramjee and George Varghese, EndRE: An End-System Redundancy Elimination Service for Enterprises, NSDI 2010, San Jose, CA

[45] Ashok Anand, Vyas Sekar and Aditya Akella, SmartRE: An Architecture for Coordinated Network-wide Redundancy Elimination, SIGCOMM 2009, Barcelona, Spain

[46] John Breeden II, "Smart-phone battery life could double without better batteries", Nov 14, 2012

[47] Andy Boxall, "When will your phone battery last as long as your kindle", December 5, 2012

[48] Imielinski, T. and Navas, J.C. (1999). GPS-based geographic addressing, routing, and resource discovery. Comms. ACM Vol. 42, No. 4, pp. 86-92.

[49] Hightower, J. and Borriello, G. (2001). Location Systems for Ubiquitous Computing. IEEE Computer, Vol. 34, No. 8 , August, pp. 57-66.

[50] Harter, A., Hopper, A., Steggles, P., Ward, A. and Webster, P. (2002). The Anatomy of a Context-Aware Application Wireless Networks, Vol. 8, No. 2-3, Mar-May, pp. 187-197.

[51] Hightower, J., Brumitt, B. and Borriello, G. (2002). The Location Stack: A Layered Model for Location in Ubiquitous Computing. Proceedings of the 4th IEEE Workshop on Mobile Computing Systems \& Applications (WMCSA 2002), Callicoon, NY, USA, June, pp. 22-28.

[52] Graumann, D., Lara, W., Hightower, J. and Borriello, G. 
(2003). Real-world implementation of the Location Stack: The Universal Location Framework. Proceedings of the 5th IEEE Workshop on Mobile Computing Systems \& Applications (WMCSA 2003), Monterey, CA, USA, October, pp. 122-128.

[53] Ko, Y., \& Vaidya, N. H. (2000). Location-aided routing (LAR) in mobile ad hoc networks. Wireless Networks, 6(4), 307-321.

[54] Liao, W.-H., Tseng, Y.-C., \& Sheu, J.-P. (2001). GRID: a fully location-aware routing protocol for mobile ad hoc networks. Telecommunication Systems, 18(1), 37-60.

[55] Kuhn, F., Wattenhofer, R., Zhang, Y., \& Zollinger, A. (2003). Geometric ad-hoc routing: of theory and practice. In Proceedings of the ACM (PODC'03) (pp. 63-72).

[56] Jiang, X., \& Camp, T. (2002). Review of geocasting protocols for a mobile ad hoc network. In Proceedings of the Grace Hopper Celebration (GHC).

[57] Ko, Y. \& Vaidya, N. H. (1999). Geocasting in mobile ad hoc networks: location-based multicast algorithms. In Proceedings of the IEEE (WMCSA'99) (pp. 101).

[58] Mauve, M., Fuler, H., Widmer, J., \& Lang, T. (2003). Position-based multicast routing for mobile ad-hoc networks (Technical Report TR-03-004). Department of Computer Science, University of Mannheim.

[59] Xu, Y., Heidemann, J., \& Estrin, D. (2001). Geographyinformed energy conservation for adhoc routing. In Proceedings of the ACM/IEEE (MOBICOM'01) (pp. 70-84).

[60] Hu, Y.-C., Perrig, A., \& Johnson, D. (2003). Packet leashes: a defense against wormhole attacks in wireless ad hoc networks. In Proceedings of the INFOCOM' 03 (pp. 19761986).

[61] Patwari, N., Hero III, A. O., Perkins, M., Correal, N. S., \& O'Dea, R. J. (2003). Relative location estimation in wireless sensor networks. IEEE Transactions on Signal Processing, 51(8), 2137-2148.

[62] Baldauf, M., Dustdar, S., \& Rosenberg, F. (2007). A Survey on Context Aware Systems. International Journal of Ad Hoc and Ubiquitous Computing, Inderscience Publishers. forthcoming. Pre-print from: http://www.vitalab.tuwien.ac.at/ florian/ papers/ijahuc2007.pdf

[63] Hong, D., Chiu, D.K.W., \& Shen, V.Y. (2005). Requirements elicitation for the design of context-aware applications in a ubiquitous environment. In Proceedings of ICEC'05 (pp. 590-596).

[64] Neeraj Tantubay, Dinesh Ratan Gautam and Mukesh Kumar Dhariwal, A Review of Power Conservation in Wireless Mobile Ad hoc Network (MANET)", International Journal of computer Science Issues, Vol 8, Issue 4, No 1, July 2011.

[65] Wenrui Zhao, Mostafa Ammar and Ellen Zegura, "A Message Ferrying Approach for Data Delivery in Sparse Mobile Ad Hoc Networks", MobiHoc'04, May 24-26, 2004, Roppongi, Japan.
About Author (s):

Associate Professor Nawaz Mohamudally works at University of Technology, Mauritius (UTM) and has undertaken supervision of MPhil/PhD Students for many years.

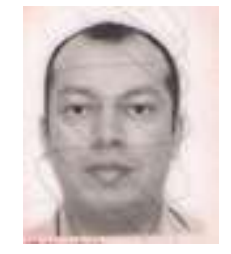

M. Kaleem Galamali is a part-time student (achieved M Phil Transfer on 28.10.2014, currently $\mathrm{PhD}$ student) at UTM under supervision of A.P. Nawaz Mohamudally. 